\title{
Modulation of central nociceptive transmission by manual pressure techniques in patients with migraine: an observational study
}

\section{Willem De Hertogh ( $\nabla$ willem.dehertogh@uantwerpen.be )}

Department of Rehabilitation Sciences and Physiotherapy, Faculty of Medicine and Health Sciences,

University of Antwerp

\section{Andreas Amons}

Health Care Center, Hoofddorp

\section{Lise Van daele}

Department of Rehabilitation Sciences and Physiotherapy, Faculty of Medicine and Health Sciences, University of Antwerp

\section{Ellen Vanbaelen}

Department of Rehabilitation Sciences and Physiotherapy, Faculty of Medicine and Health Sciences, University of Antwerp

\section{René Castien}

Faculty of Behavioural and Movement Sciences. Vrije Universiteit Amsterdam, Amsterdam Movement Sciences. Amsterdam

\section{Research Article}

Keywords: Migraine, Headache, Neck Pain, Referred Pain

Posted Date: March 8th, 2022

DOI: https://doi.org/10.21203/rs.3.rs-1413149/v1

License: (c) (i) This work is licensed under a Creative Commons Attribution 4.0 International License. Read Full License 


\section{Abstract}

Background Manual pressure techniques are used in the upper cervical spine to provoke and reduce the familiar headache in patients with migraine. So far, information is scarce on which segmental levels and myofascial structures provocation and reduction occur. Also, the required dosage (amount of pressure, number of repetitions and duration) has not been objectified yet. Therefore, we assessed the controlled application of manual pressure to provoke and reduce headache in patients with migraine.

Methods Thirty patients with migraine were examined interictally. Manual pressure was applied at four sites being the posterior arch of $\mathrm{C} 1$, the articular pillar of $\mathrm{C} 2$, the Rectus Capitis Posterior Major muscle and the Obliquus Capitis Inferior muscle, bilaterally. Pressure was constantly measured via force sensors. On sites where the familiar headache was provoked, the pressure was sustained to induce pain reduction. This was repeated three times. Provocation of familiar headache (yes/no), headache intensity (numerical pain rating scale), time to obtain reduction of the headache (seconds) and applied pressure $\left(\mathrm{g} / \mathrm{cm}^{2}\right)$ were recorded.

Results Provocation of the familiar headache occurred on at least one of the posterior arches in $92 \%$ of cases, one of the articular pillars of C2 in $65.3 \%$, one of the Rectus Capitus Major muscles in $84.6 \%$ and one of the Oblique Capitis Inferior muscles in $76.9 \%$. The applied mean pressure ranged from 0.82 $\mathrm{kg} / \mathrm{cm}^{2}$ to $1.2 \mathrm{~kg} / \mathrm{cm}^{2}$ across all measurements. Maintaining the pressure resulted in a significant reduction in headache pain intensity between the start and the end of each of three consecutive trials $(p<0.04)$. This reduction was obtained more rapidly in the third application than in the first application $(p=0.03)$.

Conclusion Manual pressure at the upper cervical segments provokes familiar referred headache in migraine, with a low pressure. Maintaining the pressure reduces the referred head pain significantly, indicating modulation of central nociceptive transmission. The underlying neurophysiological mechanisms need to be further elucidated.

\section{Background}

Migraine is a common primary headache type with an estimated global prevalence of $15.3 \%$ (1). As a recurrent and often life-long headache disorder, migraine has a high personal and socio-economic impact (2). Besides pharmacological interventions, also non-pharmacological interventions are considered to offer an efficient approach for migraine (3). Most physical treatments are targeted at the neck. Not surprising since people with migraine frequently report neck pain in the pre-, post, and ictal phases of the migraine attack (4-6). This co-occurrence of headache and neck pain seems to be explained by common nociceptive innervation of the head and neck at the trigeminal-cervical complex $(7,8)$. Irrespective if neck pain is a symptom or a contributing factor of the migraine attack, this merge of nociceptive innervation at the trigeminal-cervical complex provides a rationale for referred pain from the neck to the head but also for interventions targeted at the cervical spine $(9,10)$. 
Referred pain to the head can be provoked by pressure or stretch on cervical myofascial structures such as muscles, ligaments, and joints. Provocation of headache, by techniques using a combination of movement and manual pressure on upper cervical myofascial structures, may distinguish patients with migraine from healthy controls (10-12). Repetition and sustained pressure during the application of these specific techniques at the upper cervical spine may also reduce referred pain to the head and appears to be a prognostic factor for the success of physiotherapy treatment of patients with migraine $(13-15)$. Not only the intensity of the referred headache seems to be affected by the repetition of these techniques, but it also induces a change in the brainstem by altering the nociceptive blink reflex (13).

Although provocation and reduction of referred head pain can be used to assess and treat patients with headaches, information about the applied pressure during these tests and the relevance of these specific tests is missing.

Our study explores if familiar headache can be provoked and reduced by manual pressure at the upper cervical spine in patients with migraine. The pressure to obtain this provocation and reduction of referred pain has not been objectified yet. Therefore, we will measure the applied pressure and the immediate effects on referred pain to the head during the application of these techniques in patients with migraine. This information is mandatory to gain further insight into the underlying pathophysiological mechanism and to verify if a change in the applied pressure does not cause the observed decrease.

The aims of this study are first to determine if manual pressure can provoke referred pain to the head; second to determine if sustained manual pressure can reduce referred pain to the head; and third, to constantly monitor the amount of pressure during manual pressure.

\section{Methods}

Design

A prospective observational study was conducted and reported according to the STROBE criteria for observational studies. https://www.strobe-statement.org. The Ethics committee of Antwerp University Hospital approved this study (trial registration: B300201734328). All patients provided written informed consent before their participation.

\section{Patients}

Patients with migraine were recruited from primary health care centers with specific focus on and expertise in headache and neck pain. All patients were initially screened for eligibility by a telephone interview using a structured questionnaire. Patients were diagnosed according to the criteria of the International Classification of Headache Disorders (III) by a general practitioner or neurologist (14).

Patients were excluded in case of other headaches, medication overuse, rheumatoid disorder, chronic diseases (i.e. fibromyalgia), a recent history of neck/head trauma (i.e. whiplash), anaesthetic block in the past month, pregnancy and symptoms of concomitant illness. Furthermore, migraine needed to be 
accompanied by neck pain and a good understanding of the Dutch language was required as all information, instructions, and questionnaires were in Dutch. Patients were asked to keep a headache diary for four weeks to confirm the diagnosis and frequency of migraine. Measurements were planned interictally, and it was not allowed to take analgesics or muscle relaxants twenty-four hours before the examination.

Measurements

These consisted of the completion of a headache diary (headache frequency and headache intensity), two questionnaires (Headache Impact Tests, HIT-6 and Central Sensitization Inventory), the assessment of Pressure Pain Thresholds (PPTs) and measurement of pressure during MPT.

Headache characteristics

The headache diary was used to calculate the headache frequency (days/month) and mean headache intensity on a Numerical Pain Rating Scale (NPRS). The NPRS is a scale with 11-points, with 0 indicating no pain and ten indicating as intense as one could imagine $(14,15)$ and is used to rate the intensity of the headache and neck pain. The mean headache intensity was calculated by dividing the sum of all NPRSscores on headache days and the mean of all noted headache days.

Questionnaires

The Headache Impact Test 6 (HIT-6) measures the adverse impact of headache on social functioning, role functioning, vitality, cognitive functioning and psychological distress and measures the severity of headache pain. This questionnaire consists of six items that need to be answered on a five-point scale ranging from never to always. The total score varies between 36 and 78, with a higher score according to a more significant impact. HIT-6 scores are divided into four severity levels; little or no impact $(\leq 49)$, some impact (50-55), substantial impact (56-59) and severe impact ( $\geq 60)$. The HIT-6 is reliable and valid in patients with headaches, equally in patients with chronic migraine $(16,17)$.

The central sensitization inventory (CSI) is also a self-report scale designed to highlight the possible presence of a central sensitization syndrome. The first part, Part A, assesses 25 health-related symptoms common to central sensitization syndromes. Total scores range from 0-100, where a cut-off score of 40 provides a clinically relevant guide to assume the possible presence of a central sensitization syndrome (18). Part B collects the presence of previous diagnoses of seven separate central sensitization syndromes, including migraine. The Dutch version used in this study has good internal consistency for the total score on 3 out of 4 domains, good discriminative power and excellent test-retest reliability (19).

Pressure Pain Thresholds

Pressure Pain Thresholds (PPT) were assessed with the Somedic algometer with a $1 \mathrm{~cm}^{2}$ probe and are expressed in $\mathrm{kPa} / \mathrm{cm}^{2}$. This algometer has excellent construct validity and high intrarater reliability in people with migraine (20) (21). This was done by examiner 1 (E.V.), who had training for these 
measurements of 10 hours. In total, three measurements were performed on the midpoint of the upper trapezius, thenar and anterior tibial anterior muscle, bilaterally. The pressure was gradually increased $(50 \mathrm{kPa} / \mathrm{sec})$ until the feeling of only pressure changed into the feeling of pressure and pain.

The participant had to push a button of a hand-held switch. Once the participant had pushed the button, the recorded value on the display of the algometer was noted (20).

Manual Pressure Techniques

The MPTs were performed by two musculoskeletal physiotherapists (W.D.H. and R.C.) with each over 20 years of experience in assessing and treating patients with cervical spine disorders. Four techniques were performed bilaterally.

The first two techniques are described by Watson et al. (10).The patient lies in a supine position, and pressure with the thumb is applied at the posterior arch of $\mathrm{C} 1$, with the participant's head in approximately 20 degrees of contralateral rotation. By adding a slight rotation of the head towards the thumb, stress is applied to the joint of C0-1. In preparation for the second technique, pressure with the thumb is directed to the articular pillar of $\mathrm{C} 2$ with the participant's head in approximately 30 degrees of contralateral rotation to passively stress the joint of $\mathrm{C} 2-3$.

The third and fourth techniques are performed with the patient in a prone position and the cervical spine in a neutral position. Pressure with the thumb is given deep towards the occiput to stretch the Rectus Capitis Major muscle (third technique). At a lower level, pressure with the thumb was directed towards the spinous process of $\mathrm{C} 2$ and attempted to stretch the Obliquus Capitis muscles. (fourth technique). A schematic representation of technique 3 and 4 is presented in Fig. 1.

The outcome of these MPTs was defined as positive (yes/no) if provocation of the familiar headache occurred within 5 seconds. In all positive cases, the intensity of the provoked pain was registered via an NPRS.

Registration of the applied thumb pressure

During the MPT, the thumb pressure of the assessor was measured constantly using force-sensing resistor sensors $\left(1.23 \mathrm{~cm}^{2}\right)$ that were placed on the tip of the thumb (Fig. 2) and registered by CAPTIV software (CAPTIV-L7000, www.teaergo.com). These sensors measure the applied pressure in $\mathrm{kg} / \mathrm{cm}^{2}$. During the examination, a third assessor was in control of the software so that the examiner, who performed the MPT, was blinded for the outcome on the applied pressure. The third assessor also recorded the patients reported outcome on the MPT.

\section{Procedures}

NPRS scores for headache and neck pain were obtained before the measurements. When NPRS scores were $\leq 3 / 10$, it was considered that pain did not influence the tests. PPTs were measured. 
MPT measurements were performed in two steps. In the first step we verified if and at which site the familiar headache could be provoked. The outcomes of the MPTs being provocation of headache (yes/ no) and corresponding headache intensity (NPRS-score) were recorded.

In the second step, the MPTs were performed and now maintained for both the provocation ánd reduction of the referred pain to the head. Pressure was maintained until the NPRS score of the headache was reduced to $<2 / 10$ or after a maximum of 120 seconds. During the application of the MPTs, the NPRS scores were noted every 15 seconds and the applied pressure was registered constantly via the FSR sensors.

Sufficient time was left between the two steps so there was no residual pain.

\section{Data analysis}

Data were analyzed with the SPSS version 27 Software (IBM Corp. Released 2020. IBM SPSS Statistics for Windows, Version 27.0. Armonk, NY: IBM Corp).

Descriptive data and headache characteristics were collected from all patients. Descriptive analysis was also performed for the outcomes of the MPT.

Normality of quantitative data was assessed by means of the Kolmogorov-Smirnov test. Parametric tests were used for quantitative data with a normal distribution. Conversely, non-parametric tests were used for qualitative data and quantitative data without normal distribution.

To study the reduction of the provoked headache, comparisons of NPRS scores before and after each trial were made via (paired samples T-test or) and across all three trials via a Friedman test. Changes in time needed to obtain the reduction were analyzed via a Friedman test and consequent Mann-Whitney $U$ tests.

A 2-tailed $p$-value $<.05$ was chosen as the level of significance.

\section{Results}

Demographic data and headache characteristics

Thirty patients with migraine, three men and 27 women, participated in this study. The characteristics of the patients are summarized in Table 1. 
Table 1

Demographic data and headache characteristics of patients with migraine $(n=30)$

\section{Demographics}

Gender (male/female)

$3 / 27$

Age in years, mean (SD)

$41(13.4)$

\section{Headache characteristics}

Length of history of migraine in years, mean (SD) $21.5(14.9)$

Headache pain intensity (Numerical pain rating scale) $\left(^{*}\right)$, mean (SD) $6.2(1.4)$

Frequency in days per month $(*)$, mean (SD) $8.9(6.4)$

Headache Impact Test 6, mean (SD)

$63.4(4.2)$

\section{Pain measurements}

Central Sensitization Index A, mean (SD)

$42.9(12.6)$

Pressure Pain Thresholds in kPa, mean (SD)

- Midpoint Upper Trapezius muscle Left- side

$290.85 \pm 168.51$

- Thenar Left-side

$295.68 \pm 131.78$

- Anterior Tibial muscle Left-side

$399.85 \pm 289.00$

- Midpoint Upper Trapezius muscle Right-side

$312.19 \pm 200.54$

- Thenar Right-side

$318.37 \pm 125.28$

- Anterior Tibial muscle Right-side

$380.70 \pm 257.23$

${ }^{*}=$ headache diary $)$

Provocation of headache by MPT

Familiar headache was provoked in all 30 patients, but not at all sites. The number of locations provoking the familiar headache ranged from 1 to all 8 locations (median: 5, IQR: 3-7)

Table 2 shows the percentage of provocation of headache for all eight sites. 
Table 2

Provocation of familiar headache and corresponding mean Numerical Pain Rating Scale (NPRS) and registered pressure $\left(\mathrm{kg} / \mathrm{cm}^{2}\right)$. SD = standard deviation

\begin{tabular}{|c|c|c|c|c|}
\hline Measured site & & $\begin{array}{l}\text { Overall \% } \\
\text { provoked }\end{array}$ & $\begin{array}{l}\text { NPRS } \\
\text { (mean } \pm \\
\text { SD) }\end{array}$ & $\begin{array}{l}\text { Registered pressure }\left(\mathrm{kg} / \mathrm{cm}^{2},\right. \\
\text { mean } \pm \text { SD) }\end{array}$ \\
\hline \multirow[t]{3}{*}{$\mathrm{CO}-1$} & Left side & $76.7 \%$ & $\begin{array}{l}5.04 \pm \\
1.8\end{array}$ & $0.93 \pm 0.50$ \\
\hline & Right side & $76.7 \%$ & $\begin{array}{l}5.48 \pm \\
1.8\end{array}$ & $1.00 \pm 0.35$ \\
\hline & $\begin{array}{l}\text { One of both } \\
\text { sides }\end{array}$ & $93.3 \%$ & & \\
\hline \multirow[t]{3}{*}{$C 2-3$} & Left side & $43.3 \%$ & $\begin{array}{l}5.62 \pm \\
1.7\end{array}$ & $0.82 \pm 0.35$ \\
\hline & Right side & $53.3 \%$ & $\begin{array}{l}5.44 \pm \\
1.9\end{array}$ & $0.99 \pm 0.40$ \\
\hline & $\begin{array}{l}\text { One of both } \\
\text { sides }\end{array}$ & $56.7 \%$ & & \\
\hline \multirow{3}{*}{$\begin{array}{l}\text { Rectus Capitis } \\
\text { Major } \\
\text { muscle }\end{array}$} & Left side & $63.3 \%$ & $\begin{array}{l}5.00 \pm \\
1.7\end{array}$ & $1.17 \pm 0.42$ \\
\hline & Right side & $70.0 \%$ & $\begin{array}{l}4.57 \pm \\
1.8\end{array}$ & $1.13 \pm 0.47$ \\
\hline & $\begin{array}{l}\text { One of both } \\
\text { sides }\end{array}$ & $83.3 \%$ & & \\
\hline \multirow{3}{*}{$\begin{array}{l}\text { Oblique Inferior } \\
\text { Muscle }\end{array}$} & Left side & $53.3 \%$ & $3.4 \pm 1.5$ & $0.95 \pm 0.51$ \\
\hline & Right side & $50.0 \%$ & $\begin{array}{l}4.87 \pm \\
2.0\end{array}$ & $0.85 \pm 0.53$ \\
\hline & $\begin{array}{l}\text { One of both } \\
\text { sides }\end{array}$ & $70.0 \%$ & & \\
\hline
\end{tabular}

During this provocation, mean thumb pressures ranged from $0.81 \mathrm{~kg} / \mathrm{cm} 2$ to $1.2 \mathrm{~kg} / \mathrm{cm}^{2}$ across all measurements.

Reduction of headache by sustained MPT

Reduction of headache during three consecutive repetitions of MPT is measured via the headache intensity and via the time needed for the reduction to occur.

\section{Headache intensity}


In 23 patients, change in headache intensity was monitored at sites where the familiar headache was reproduced. In 21 patients there was a reduction in headache intensity up to an NPRS of $<2 / 10$ at the end of the last repetition. The mean headache intensity decreased during the first repetition from 4.48 points \pm 1.82 points to 1.82 points \pm 1.55 points, during the second repetition from 4.05 points \pm 1.84 points to 1.23 points \pm 1.51 points and during the third repetition from 3.71 points \pm 1.99 points to 1.02 points \pm 1.23 points. This reduction is significant (paired T-test, $p<0.001$ ). At the start of each repetition, the provoked headache is always slightly less intense (ANOVA, $p=0.05$ ). These findings are visually represented in Fig. 3.

Time for reduction to occur

With the three repetitions, the decrease in headache intensity occurred faster. A significant difference in time (seconds) was found between the first and second repetition (Wilcoxon Signed Rank test, $p=.002$ ), the second and the third (Wilcoxon Signed Rank test, $p=.002$ ) and between first and third (Wilcoxon Signed Rank test, $\mathrm{p}<.001)$. This is represented visually in Fig. 4.

Registered pressure

The registered pressure during the sustained MPT did not differ significantly between the first, second and third trials (see Table 3 ). 
Table 3

Comparison of the pressure applied during the MPTs in three consecutive trials ( ${ }^{*}$ Friedman test).

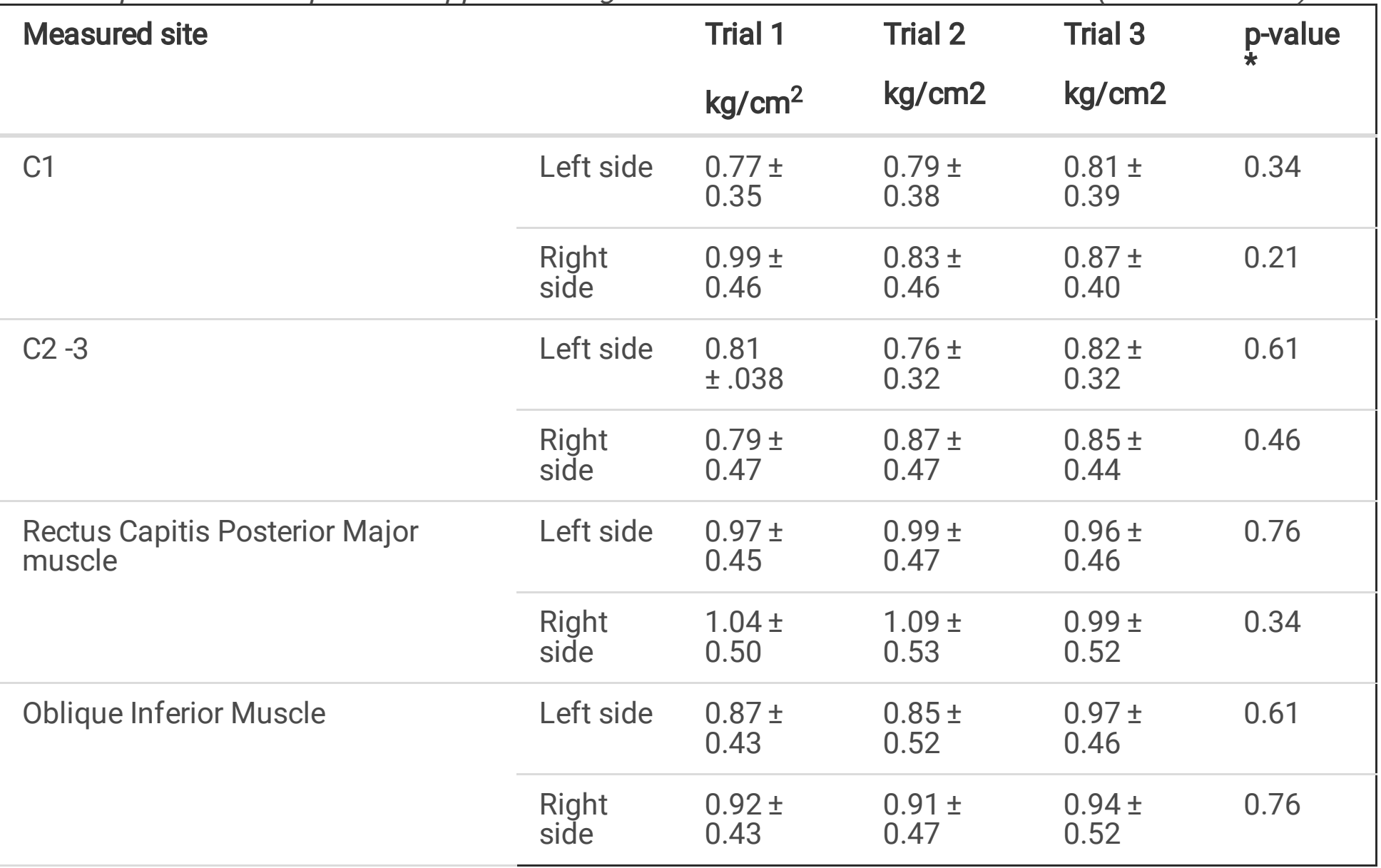

During each application, a variation (decline or increase) of $9 \%$ in thumb pressure occurred. An example of a thumb pressure/time graph is presented in Fig. 3.

\section{Discussion}

This study showed that manual pressure with low force can provoke referred pain to the head in patients with migraine in the interictal phase. Sustaining the MPT results in a reduction of the referred head pain. Repeating the MPTs results in less intense pain provocation and a faster reduction in referred head pain.

The provocation of referred head pain occurred even with low pressures. The maximum was only 1,78 $\mathrm{kg} / \mathrm{cm}^{2}$. This is low compared to e.g. the $4 \mathrm{~kg} / \mathrm{cm}^{2}$ reference value for tender point examination in the diagnostic criteria for fibromyalgia of The American College of Rheumatology (ACR) 1990 (22). The fact that such low pressures can induce referred pain to the head, suggests increased mechano-sensitivity in the upper-cervical region and an altered central pain processing in migraine (8).

Our MPTs are similar to those applied by Watson et al. $(10,13)$ and Luedtke $(11)$. By combining pressure and movement in the upper cervical region, pressure is not only applied on articular but also on myofascial structures such as the suboccipital muscles Rectus Capitis Posterior Major and Obliquus Capitis Inferior muscle. Consequently, they can all serve as a source of nociceptive stimulation on the trigeminocervical system. 
A recent study found that patients with migraine where head pain could be provoked on palpation were more likely to improve after a physiotherapy intervention (12). This may indicate that modulation of nociceptive transmission at the TCC may be of potential benefit in treating the neck in patients with migraine.

Provocation of referred pain to the head was more frequent at higher cervical levels. The high percentage $(93 \%)$ of provocation at $\mathrm{C} 1$ is in line with Watson \& Drummond (10). Comparisons with literature for the MPTs at the Rectus Capitis Posterior Major muscles and Inferior Oblique muscles are hard to make since these techniques are not yet described as such. However, the provocation of characteristic referred head pain by muscle tissues is described in studies investigating active trigger points in patients with migraine (23-25). The observed provocation of referred head pain is assumed to be caused by a combination of stretch and applied pressure on myofascial tissues (muscles, ligaments), resulting in increased nociceptive input to second-order neurons at the pars caudalis of the trigeminal-cervical complex. All manual pressure techniques were applied in the upper cervical area with a direct neuro-anatomical relation and nociceptive impact on the trigeminal-cervical complex (8).

We not only provoked the familiar head pain but reduced it by sustaining and repeating the MPTs three times. Similar to the study of Watson \& Drummond, a significant reduction of the provoked pain intensity between the start and end of each trial occurred. During the application of the MPTs, we monitored how many seconds it took to obtain this reduction. In the three consecutive trials, this reduction occurred faster. One could argue that, during the MPT the thumb pressure decreased, resulting in a less provocative stimulus. However, we registered a pressure variation of only $9 \%$. Compared to the distribution of normative data from the pincer grip, this is a minimal variation (26). Therefore we are confident that the reduction of headache during the MPTs cannot be explained by a decrease of the applied pressure.

The characteristic headache could be provoked on both sides. This can be explained by the side-shifting character of migraine. In our sample about half of the patients did not have a dominant headache side. The provocation of familiar headache on both sides may imply that hyperexcitability at the level of the spinal dorsal horn of C1-2 is not restricted to one side. The dysfunctional activity of supraspinal descending inhibitory pathways may lead to hyperexcitability at multiple levels at both sides and may explain the occurrence of headache and altered mechanosensitivity on both sides $(8,27-29)$.

During the provocation and reduction of the referred pain to the head, most patients experienced their characteristic headache as during a migraine attack. Further, the referred pain to the head showed a pattern of referred pain that appears to be identical to the characteristics of somatic referred pain and explained by the hyperexcitability model described by Graven-Nielsen (28). According to the key points of somatic referred pain, we observed during the trials that (i) a firm local and painful stimulus on myofascial structures was able to initiate, with a short time delay, a referred pain sensation in a distant somatic structure, (ii) was felt as a deep sensation, (iii) appeared to be semi-directional (i.e. from the neck to the head) and (iiii) that the referred pain inhibited over time and diminished before the local pain (28). 
This provocation and reduction of referred pain may indicate modulation of central neural transmission of nociception. Sustained MPTs are supposed to affect the nociceptive modulating system by constant and repeated pressure on specific locations in the upper cervical region and affecting the TCC through afferent pathways. The neurophysiological and behavioral background of the inhibitory effects of repetitive pain stimuli is described in different models such as counterirritation and habituation (30-32). Activation of descending nociceptive inhibitory pathways has been determined in both concepts. The typical decrease of initially referred headache by each and after three (our study) or four trials (13) of sustained MPT show similar characteristics as described for conditioned pain models, suggesting activation of descending nociceptive inhibitory pathways.

All our patients suffered from migraine, diagnosed according to the ICHD III criteria for migraine by a neurologist or general practitioner, and neck pain. This reflects the characteristics of patients that ask for cervical spine treatment in daily practice (33). The co- occurrence of neck pain may have led to a preselection of patients who are more sensible to provocation of referred head pain. Compared to Watson \& Drummond, in a similar percentage of patients the characteristic headache could be provoked by the MPT (10). Almost all (21 out of 23) patients experienced a reduction of the characteristic headache when the MPT was maintained and in line with the findings of Watson \&Drummond. In the sample from Luedtke and May, where neck pain was not an inclusion criterion, the characteristic headache was only provoked in $47 \%$ of cases (11). Therefore, we cannot rule out that patients' expectations and other psychological factors may have influenced the results. Although most patients with migraine experience neck pain, we cannot generalize our findings to all patients with migraine. Repetition of our study in a different setting is needed to confirm our results.

To perform all measurements interictally, measuring moments were planned at least two days after the last migraine attack. Within the provided time frame of our study, we were able to assess the effect of the sustained MPTs in 23 patients. We perceived no information that the applied techniques provoked migraine.

Future studies are needed to verify if pressure in the upper cervical spine can provoke characteristic headache in patients with migraine without concomitant neck pain. Although modulation of nociception at the trigeminal cervical complex appears to be involved in provocation and reduction of referred head pain by MPT, more research is needed to understand and clarify the neurophysiological background of this phenomenon.

We only repeated the MPTs three times in one session. It is not yet known if more frequent repetition of the MPTs in multiple sessions could have a therapeutic effect. Further research is needed to determine if MPTs can be of value in treatment programs to reduce headache in patients with migraine. At least one trial is currently ongoing (34).

\section{Conclusion}


MPTs provoke referred pain to the head in patients with migraine. Provocation and reduction of referred pain were obtained, indicating modulation of central nociceptive transmission. The neurophysiological mechanism of provocation and reduction of headache by sustained MPT needs to be further elucidated.

\section{Declarations}

\section{Availability of data}

The datasets used and/or analysed during the current study are available from the corresponding author on reasonable request.

The authors declare not to have conflicts of interest.

\section{References}

1. Vos T, Allen C, Arora M, Barber RM, Bhutta ZA, Brown A, et al. Global, regional, and national incidence, prevalence, and years lived with disability for 310 diseases and injuries, 1990-2015: a systematic analysis for the Global Burden of Disease Study 2015. The Lancet. 2016;388(10053):1545-602.

2. Linde M, Gustavsson A, Stovner LJ, Steiner TJ, Barre J, Katsarava Z, et al. The cost of headache disorders in Europe: the Eurolight project. Eur J Neurol. 2012;19(5):703-11.

3. Gaul C, Liesering-Latta E, Schafer B, Fritsche G, Holle D. Integrated multidisciplinary care of headache disorders: A narrative review. Cephalalgia. 2016;36(12):1181-91.

4. Ashina S, Bendtsen L, Lyngberg AC, Lipton RB, Hajiyeva N, Jensen R. Prevalence of neck pain in migraine and tension-type headache: a population study. Cephalalgia. 2015;35(3):211-9.

5. Lampl C, Rudolph M, Deligianni Cl, Mitsikostas DD. Neck pain in episodic migraine: premonitory symptom or part of the attack? J Headache Pain. 2015;16:566.

6. Calhoun AH, Ford S, Millen C, Finkel AG, Truong Y, Nie Y. The prevalence of neck pain in migraine. Headache. 2010;50(8):1273-7.

7. Bartsch T. Migraine and the neck: new insights from basic data. Curr Pain Headache Rep. 2005;9(3):191-6.

8. Castien R, De Hertogh W. A Neuroscience Perspective of Physical Treatment of Headache and Neck Pain. Front Neurol. 2019;10:276.

9. Maitland GD. Vertebral Manipulation. 4th ed2013.

10. Watson DH, Drummond PD. Head pain referral during examination of the neck in migraine and tension-type headache. Headache. 2012;52(8):1226-35.

11. Luedtke K, May A. Stratifying migraine patients based on dynamic pain provocation over the upper cervical spine. J Headache Pain. 2017;18(1):97.

12. Luedtke K, Starke W, Korn Kv, Szikszay TM, Schwarz A, May A. Neck treatment compared to aerobic exercise in migraine: A preference-based clinical trial. Cephalalgia Reports. 2020;3. 
13. Watson DH, Drummond PD. Cervical referral of head pain in migraineurs: effects on the nociceptive blink reflex. Headache. 2014;54(6):1035-45.

14. Jensen MP, Turner JA, Romano JM, Fisher LD. Comparative reliability and validity of chronic pain intensity measures. Pain. 1999;83(2):157-62.

15. Williamson A, Hoggart B. Pain: a review of three commonly used pain rating scales. J Clin Nurs. 2005;14(7):798-804.

16. Kosinski M, Bayliss MS, Bjorner JB, Ware JE, Jr., Garber WH, Batenhorst A, et al. A six-item short-form survey for measuring headache impact: the HIT-6. Qual Life Res. 2003;12(8):963-74.

17. Rendas-Baum R, Yang M, Varon SF, Bloudek LM, DeGryse RE, Kosinski M. Validation of the Headache Impact Test (HIT-6) in patients with chronic migraine. Health Qual Life Outcomes. 2014;12:117.

18. Neblett R, Cohen H, Choi Y, Hartzell MM, Williams M, Mayer TG, et al. The Central Sensitization Inventory (CSI): establishing clinically significant values for identifying central sensitivity syndromes in an outpatient chronic pain sample. J Pain. 2013;14(5):438-45.

19. Kregel J, Vuijk PJ, Descheemaeker F, Keizer D, van der Noord R, Nijs J, et al. The Dutch Central Sensitization Inventory (CSI): Factor Analysis, Discriminative Power, and Test-Retest Reliability. Clin J Pain. 2016;32(7):624-30.

20. Castien RF, Coppieters MW, Durge TSC, Scholten-Peeters GGM. High concurrent validity between digital and analogue algometers to measure pressure pain thresholds in healthy participants and people with migraine: a cross-sectional study. J Headache Pain. 2021;22(1):69.

21. Bernhardt O, Schiffman EL, Look JO. Reliability and validity of a new fingertip-shaped pressure algometer for assessing pressure pain thresholds in the temporomandibular joint and masticatory muscles. J Orofac Pain. 2007;21(1):29-38.

22. Wolfe F, Smythe HA, Yunus MB, Bennett RM, Bombardier C, Goldenberg DL, et al. The American College of Rheumatology 1990 Criteria for the Classification of Fibromyalgia. Report of the Multicenter Criteria Committee. Arthritis Rheum. 1990;33(2):160-72.

23. Calandre EP, Hidalgo J, Garcia-Leiva JM, Rico-Villademoros F. Trigger point evaluation in migraine patients: an indication of peripheral sensitization linked to migraine predisposition? Eur $\mathrm{J}$ Neurol. 2006;13(3):244-9.

24. Ferracini GN, Florencio LL, Dach F, Chaves TC, Palacios-Cena M, Fernandez-de-Las-Penas C, et al. Myofascial Trigger Points and Migraine-related Disability in Women With Episodic and Chronic Migraine. Clin J Pain. 2017;33(2):109-15.

25. Fernandez-de-Las-Penas C, Cuadrado ML, Pareja JA. Myofascial trigger points, neck mobility, and forward head posture in episodic tension-type headache. Headache. 2007;47(5):662-72.

26. Werle S, Goldhahn J, Drerup S, Simmen BR, Sprott H, Herren DB. Age- and gender-specific normative data of grip and pinch strength in a healthy adult Swiss population. J Hand Surg Eur Vol. 2009;34(1):76-84.

27. Goadsby PJ, Bartsch T. On the functional neuroanatomy of neck pain. Cephalalgia. 2008;28 Suppl $1: 1-7$. 
28. Graven-Nielsen T. Fundamentals of muscle pain, referred pain, and deep tissue hyperalgesia. Scand J Rheumatol Suppl. 2006;122:1-43.

29. Castien RF, van der Wouden JC, De Hertogh W. Pressure pain thresholds over the cranio-cervical region in headache: a systematic review and meta-analysis. J Headache Pain. 2018;19(1):9.

30. Sprenger $C$, Bingel $U$, Buchel $C$. Treating pain with pain: supraspinal mechanisms of endogenous analgesia elicited by heterotopic noxious conditioning stimulation. Pain. 2011;152(2):428-39.

31. Piche $M$, Arsenault $M$, Rainville P. Cerebral and cerebrospinal processes underlying counterirritation analgesia. J Neurosci. 2009;29(45):14236-46.

32. Bingel U, Schoell E, Herken W, Buchel C, May A. Habituation to painful stimulation involves the antinociceptive system. Pain. 2007;131(1-2):21-30.

33. Moore C, Adams J, Leaver A, Lauche R, Sibbritt D. The treatment of migraine patients within chiropractic: analysis of a nationally representative survey of 1869 chiropractors. BMC Complement Altern Med. 2017;17(1):519.

34. Amons AL, Castien RF, van der Wouden JC, De Hertogh W, Dekker J, van der Horst HE. Manual therapy as a prophylactic treatment for migraine: design of a randomized controlled trial. Trials. 2019;20(1):785.

\section{Figures}
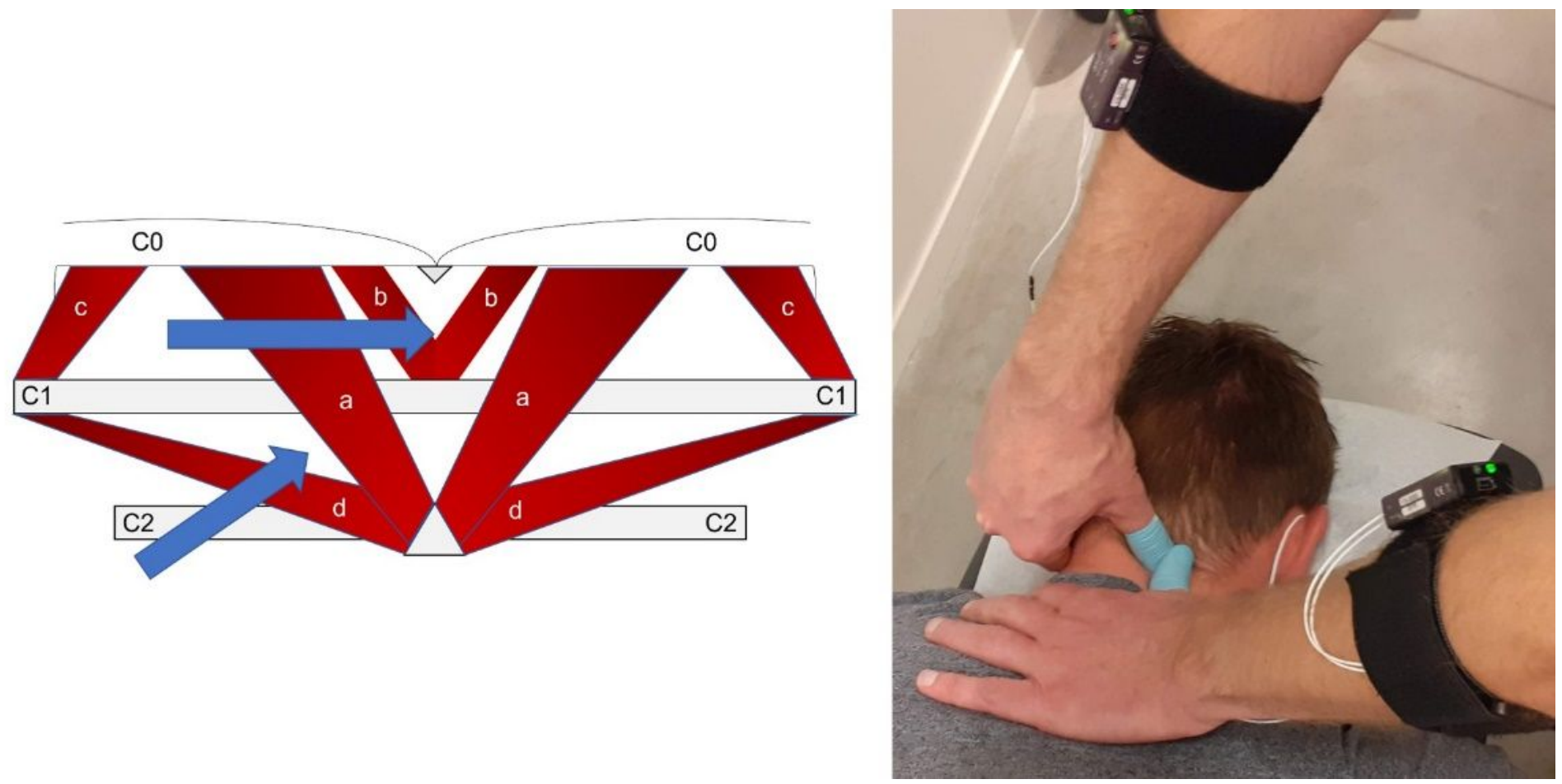

\section{Figure 1}

On the left a schematic presentation of the suboccipital muscles. Blue arrows represent directions of the applied stretches on the Rectus Capitis Posterior Muscle (top), and on the Obliquus Capitis Inferior 
Muscle (bottom). On the right demonstration of the stretch of the Rectus Capitis Posterior Muscle.

a: Rectus Capitis Posterior Maior, b: Rectus Capitis Posterior Minor, c: Obliquus Capitis Superior, d: Obliquus Capitis Inferior.

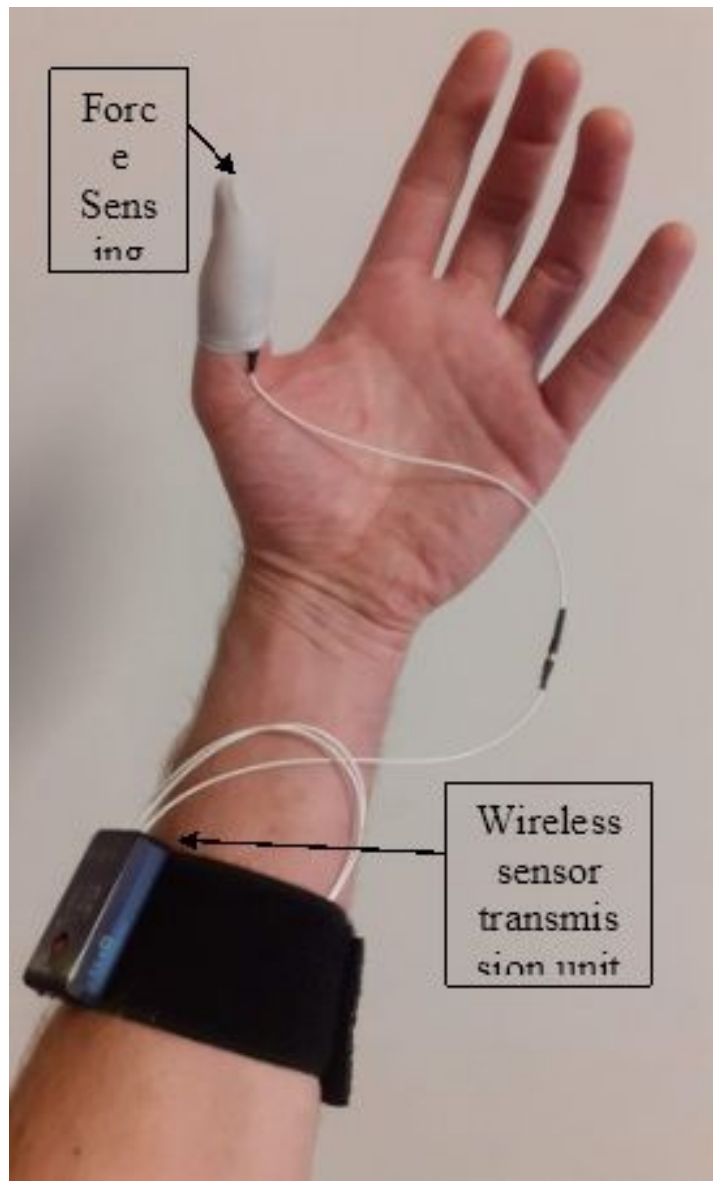

Figure 2

Experimental setup with location of the Force Sensing Resistor (FSR) Sensors on the top of the thumb. 
Headache intensity at start and end of three consecutive MPTs

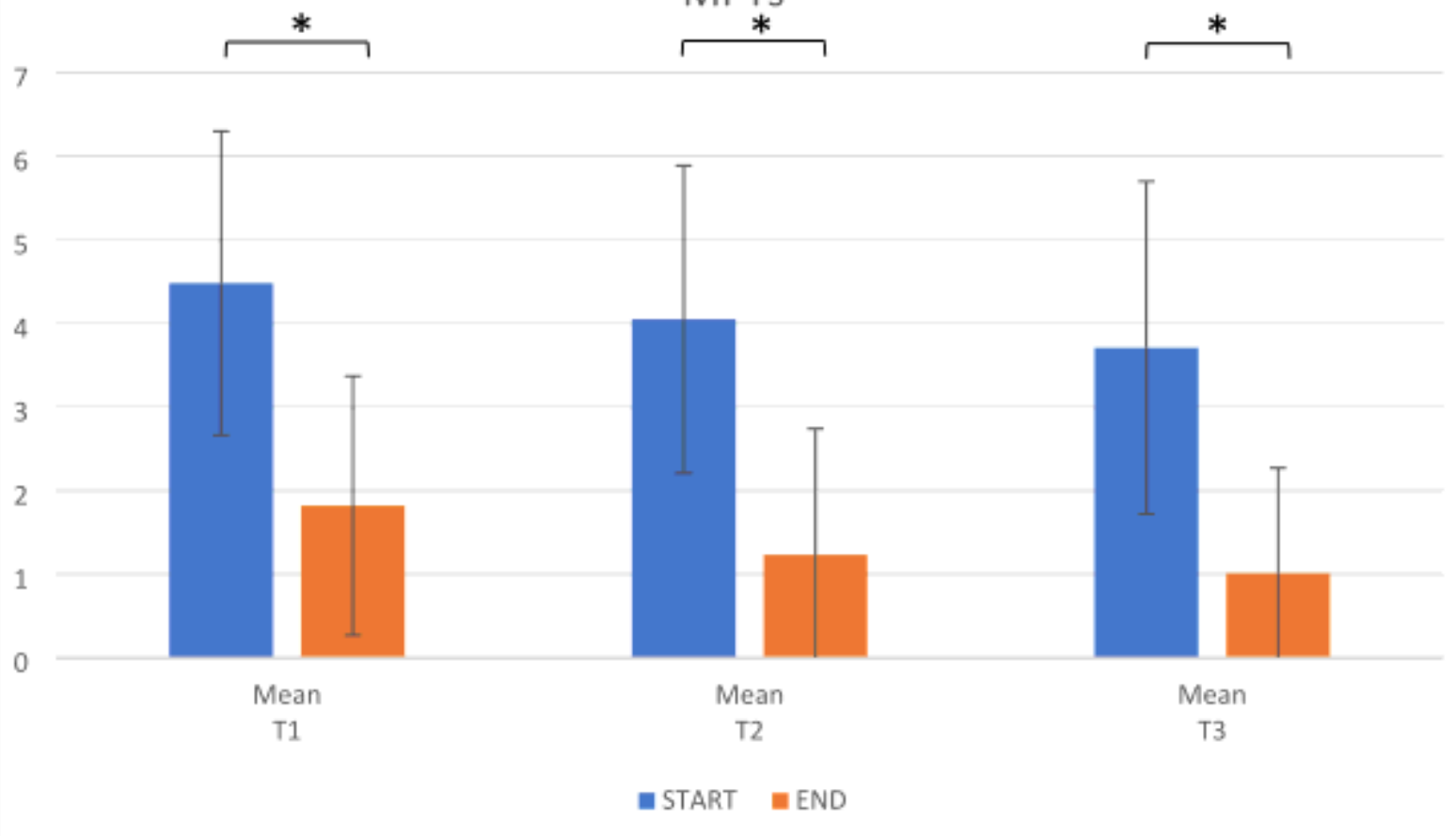

Figure 3

Headache intensity (Numerical Pain Rating Score, 0-10) at the start and end of each of the three consecutive trials (T1, T2 and T3). ${ }^{*}=p<0.001$ (paired T-test).

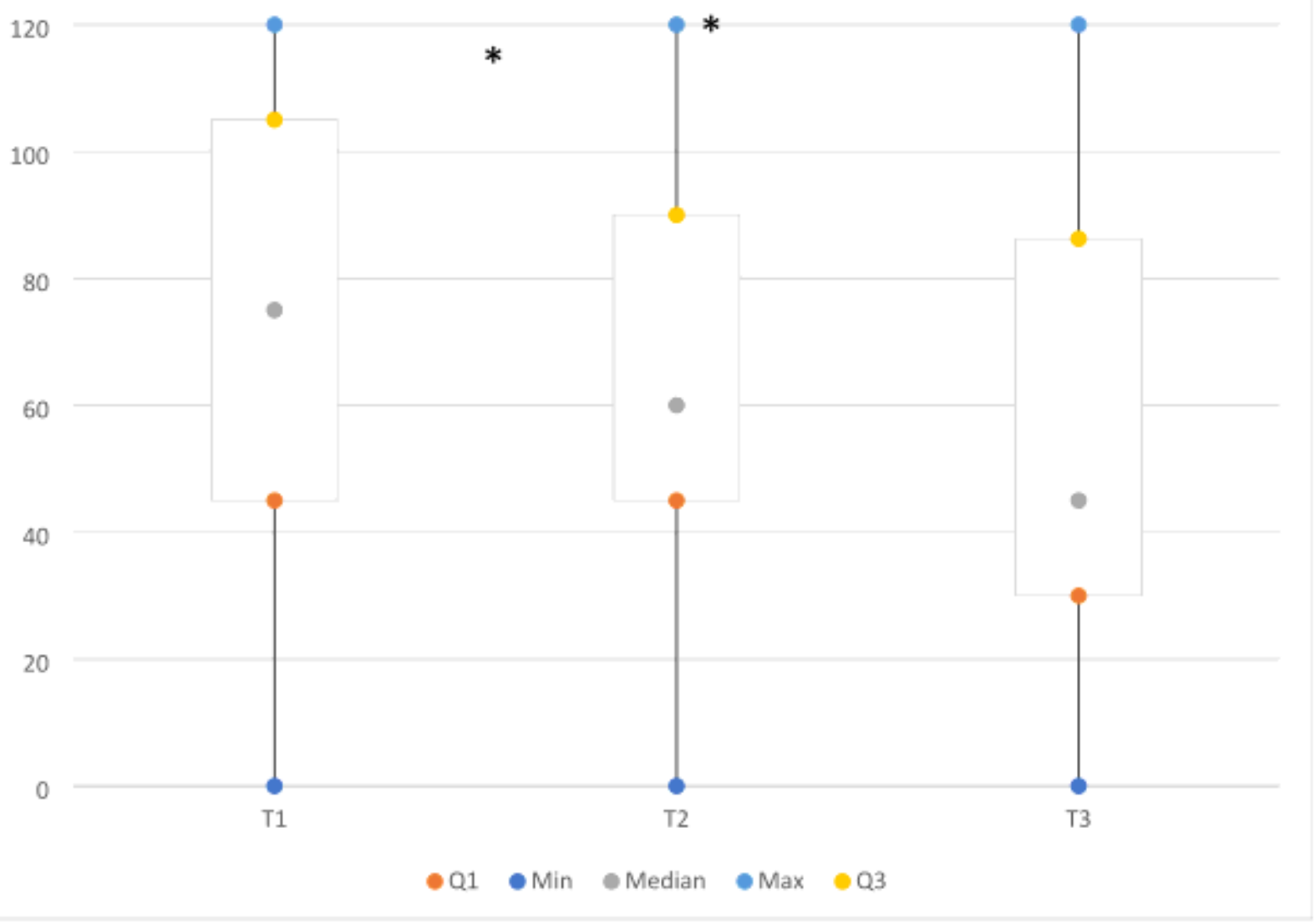

Page $17 / 18$ 


\section{Figure 4}

Time (seconds) needed to obtain a reduction of the referred head pain in three consecutive trials (T1, T2 and T3). *: significant difference (Wilcoxon Signed Rank test).

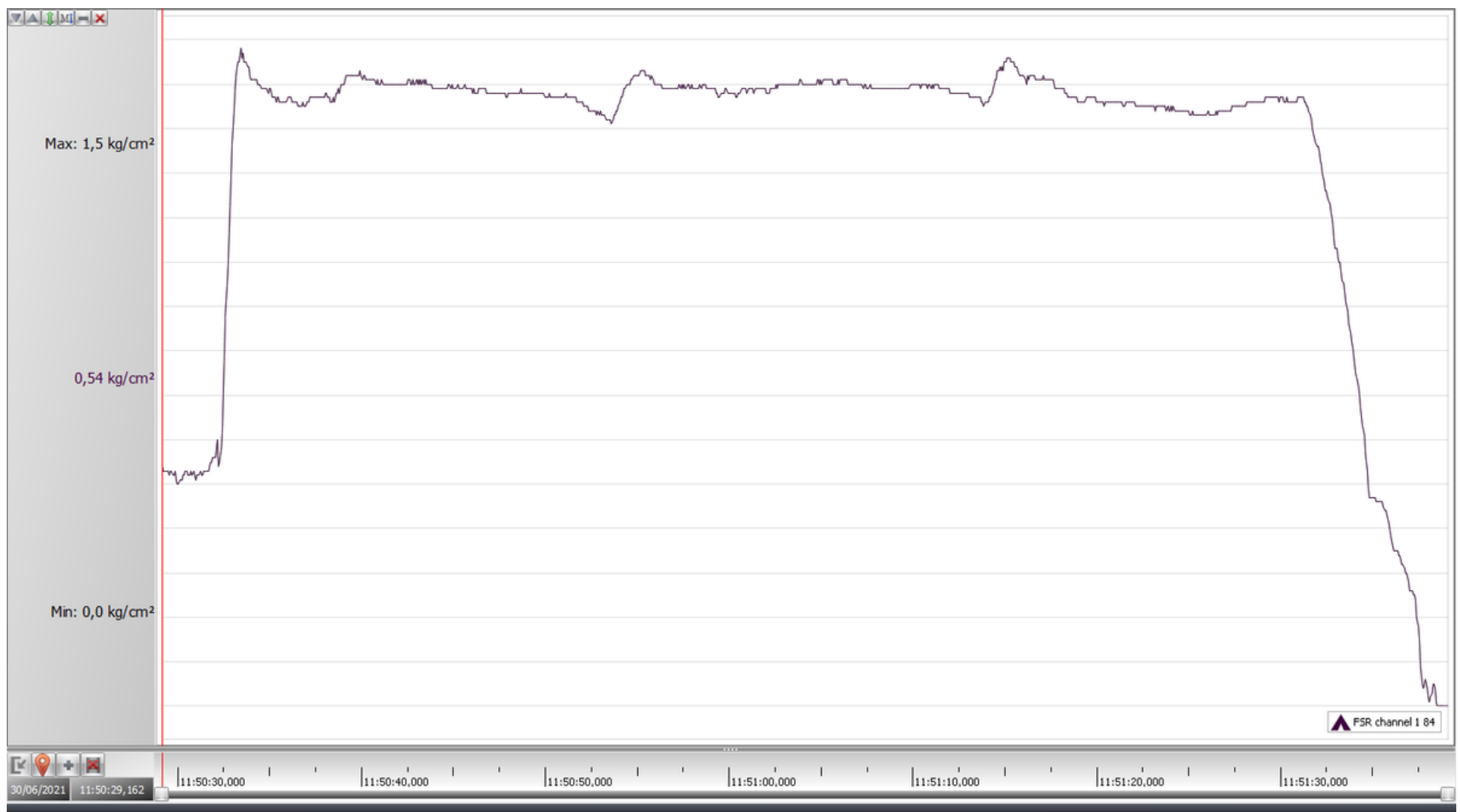

\section{Figure 5}

Example of thumb pressure during manual pressure technique. 